
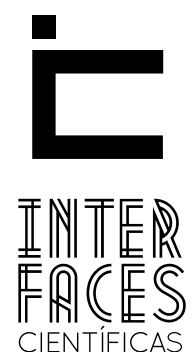

EDUCAÇÃO

\title{
A CONSTRUÇ̃̃O DA IDENTIDADE DOCENTE NA EDUCAÇÃO A DISTÂNCIA A PARTIR DO USO DE TECNOLOGIAS PARA A CRIAÇ̃̃̃ DE VÍDEOS
}

Angélica Piovesan ${ }^{1}$

\section{RESUMO}

A combinação educação e tecnologia nos possibilita investigar sobre a identidade docente. A educação a distância mais especificamente, nos faz refletir sobre as possibilidades de usar a arte e a estética na construção dialógica docente-aluno. Para a produção deste artigo, utilizamos uma parte dos resultados obtidos na realização de um estudo de caso com um professor da educação presencial e a distância, no qual enfocamos, em um dos aspectos encontrados nas entrevistas, o que se refere à produção de vídeos, videopoemas e podcasts para a educação a distância e que contribuem para a construção da identidade do professor. Convidamos para participar desta pesquisa, um docente que atua na educação a distância, utilizando as tecnologias para a produção desses materiais de aula. Acreditamos que este professor tem como uma das suas características identitárias, a criação de personagens para atuar nos vídeos, podcasts, videopoemas ou mesmo nas vídeo-aulas, e que a sua atuação diante das telas é semelhante à de um ator nos cinemas ou no teatro. Mudando a forma de trabalhar do professor e possibilitando refletir sobre sua atuação como uma nova perspectiva de ser professor, é possível criar outra forma de pensar esse professor como personagem da EAD. Entendemos que o personagem pode ser criado em diferentes situações da vida cotidiana e pode ser visto como uma das identidades assumidas em determinados momentos e circunstâncias por cada pessoa.

\section{PALAVRAS-CHAVE}

Professor da Educação a Distância. Personagem. Identidade. Teatro. Posicionamento. 


\section{ABSTRACT}

The combination of education and technology enables us to investigate about the teaching identity. Distance learning, more specifically, makes us think about the possibilities of using art and aesthetics during the dialogical teacher-student construction. In order to produce this article, it was used some of the results obtained in a case study handled by an in-loco and a long distance learning teacher. One of the highlighted aspects found in the interviews is related to video, videopoems and podcasts production for long distance learning and that contributes to build the teacher's identity. A teacher who works in long distance learning processes was invited to take part into this research, using the technology to produce the materials for his classes. We believe that this teacher has as one of his identity characteristics which help him create characters to act in videos, podcasts, videopoems or even video classes, since his acting is similar to that one which is found in cinemas and theaters. Changing the way the teacher works and allowing him some time to reflect on his performance as a teacher from a new perspective, it is possible to create another way of thinking this teacher as an EAD character. We understand that the character can be created in different situations of everyday life and can be seen as one of the assumed identities at certain times and circumstances for each person.

\section{KEYWORDS}

Long Distance Learning Teacher. Character. Identity. Theater. Motion.

\section{RESUMEN}

La combinación de la educación y la tecnología nos permite investigar la identidad docente. La educación a distancia más concretamente nos hace reflexionar sobre las posibilidades de utilizar el arte y la estética en la construcción de un diálogo entre profesor y alumno. Para la producción de este artículo, utilizamos algunos de los resultados obtenidos en la realización de un estudio de caso con un profesor de la educación presencial y a distancia, en que nos centramos en un aspecto encontrado en las entrevistas, que se refiere a la producción de videos, videopoemas y podcasts para la educación a distancia y contribuir a la construcción de la identidad del maestro. Invitamos a participar en esta encuesta un maestro que trabaja en la educación a distancia, utilizando la tecnología para producir estos materiales en la clase. Creemos que este profesor tiene como una de las características de la identidad, la creación de personajes para actuar en los videos, podcasts, o incluso en las clases de vídeo videopoemas, y que su acción en las pantallas es similar al de un actor en el cine o el teatro. Cambiar la forma en que trabajamos y que permite al profesor reflexionar sobre su actuación como una nueva perspectiva de ser un maestro puede crear otra forma de pensar el maestro como un personaje de la EAD. Entendemos que el personaje se puede crear en las diferentes situaciones de la vida cotidiana y puede ser visto como una de las identidades asumidas en determinados momentos y circunstancias de cada persona.

\section{PALABRAS CLAVE}

Profesor de Educación a Distancia. Carácter. Identidad. Teatro. Movimiento.

\section{INTRODUÇ̄̃OO}

Eu estou sempre aqui, olhando pela janela. Não vejo arranhões no céu nem discos voadores. Os céus estão explorados, mas vazios. Existe um biombo de ossos perto daqui. Eu acho que estou meio sangrando.
Eu já sei, não precisa me dizer. Eu sou um fragmento gótico. Eu sou um castelo projetado. Eu sou um slide no meio do deserto. Eu sempre quis ser isso mesmo. Uma adolescente nua, que nunca viu discos voadores, 
e que acaba capturada por um trovador de fala cinematográfica. Eu sempre quis isso mesmo: armar hieróglifos com pedaços de tudo, restos de filmes, gestos de rua, gravações de rádio, fragmentos de TV. Mas, eu sei que os meus lábios são transmutação de alguma coisa planetária. Quando eu beijo, eu improviso mundos molhados. Aciono gametas guardados. Eu sou a transmutação de alguma coisa eletrônica. Uma notícia de saturno esquecida, uma pulseira de temperaturas, um manequim mutilado, uma odalisca androide que tinha uma grande dor, que improvisou com restos de cinema e com seu amor, um disco voador.

(Fausto Fawcet ,fragmentos do texto Disco Voador)

O poema acima é um fragmento do texto "Disco Voador" de Fausto Fawcet e, a partir dele, iniciamos nossa reflexão sobre a construção identitária do professor da EAD especificamente em relação ao entrevistado da nossa pesquisa que é um professor da educação presencial e a distância de uma universidade. Odalisca Androide é o nome desse poema e nos permite refletir sobre as relações humanas e o uso da tecnologia como contribuição para a construção da identidade do professor como profissional, como docente neste estudo de caso, o que acaba propiciando novos conflitos de identidades, virtuais e reais, compostas por fragmentos dialógicos de si mesmo. Nosso entrevistado utiliza o poema Odalisca Androide em várias produções que ele realiza.

Para a produção deste artigo, utilizamos uma parte dos resultados obtidos num estudo de caso realizado com um professor da educação presencial e EAD. Enfocamos em um dos aspectos encontrados nas entrevistas, o que se refere à produção de vídeos, videopoemas e podcasts para a EAD que contribuem para a construção da identidade do $\operatorname{Dan}^{1}$ como professor.

Convidamos para participar desta pesquisa, um docente que atua na EAD, utilizando as tecnologias para a produção desses materiais de aula os quais contribuem para a sua construção identitária como professor. Os dados foram construídos a partir de entrevistas narrativas da história de vida profissional

1 Utilizamos um nome fictício para o nosso professor entrevistado do entrevistado e dos materiais disponibilizados por ele, tais como vídeos e podcasts. Utilizamos as contribuições de Bauer e Gaskell (2003), Creswell (2007), Borges e Linhares (2008) por fundamentarem sobre o método qualitativo, análise narrativa, análise de imagens e vídeos.

Trabalhar com a arte, estudar a arte, agregar conhecimentos sobre teatro, roteirização de cinema à educação, são componentes que contribuem para a construção identitária deste professor da EAD.

Dan é um professor preocupado com o aluno do curso de licenciatura. Ele busca repensar as suas contribuições como docente para a formação desses futuros professores, agregando conhecimentos adquiridos ao longo de sua história de vida acadêmica, familiar e com a sua formação em teatro na adolescência:

\begin{abstract}
Primeira aula de literatura não tem leitores, $5 \%$ são leitores, aí eu começo, deixo a aula assim, numa espécie de penumbra, faço todo mundo levantar, [...] vamos formar leitores, ta? E, eu começo fazendo exercícios de vozes com os alunos, de expressão vocal e aí a gente começa a ter consciência de como você fala, como você se expressa, é curso de formação de professor, professor vai ter que falar, vai ter que se expressar, então, tenho que ajudar nesse processo, ta? No meio desse monte de processo, eu recito milhares de poemas pra eles, esse encantamento que você vai ver nesses vídeos, recito porque tenho um monte de memórias e aí tem, tem esse poema da Odalisca Androide do Fausto Fawcet que eu recito sempre, várias vezes, que pensa essa coisa do sujeito fragmentado, que se pensa numa cultura contemporânea [...] (Professor Dan)
\end{abstract}

As escolhas de Dan em fazer determinados cursos e não outros no seu passado denominamos de posicionamentos, que são posições assumidas em determinadas situações. Para Langenhove e Harré (1999), posicionamentos podem ser compreendidos como as posições que as pessoas ocupam diante das suas escolhas sociais em sua história pessoal.

Isso quer dizer que as escolhas de Dan em fazer teatro, em formar-se em letras e especializar-se em 
literatura são fatores que auxiliam no seu presente para a sua forma de ser professor da EAD. Percebemos que as relações entre passado, presente e futuro estão em constantes modificações, o que representa um ponto de vista discutido na teoria do posicionamento. Porém, essa relação acaba divergindo do pensamento Newtoniano e Euclidiano sobre espaço e tempo, que para estes autores, é uma relação fixa e imutável (LANGENHOVE; HARRÉ,1999).

Posicionamento e identidade são conceitos que estão atrelados, pois ambos consideram que o indivíduo está em constante construção. A identidade é construída histórica e culturalmente no decorrer da trajetória de vida do ser humano e envolve as relações familiares, acadêmicas e sociais em que o sujeito deixa de ser integrado no "sentido de si" estável e se constitui como "descentrados e deslocados de seu lugar no mundo social e cultural como de si mesmo" (HALL, 2005, p. 9). A construção da identidade é algo dinâmico e constante que envolve os posicionamentos de si (HARRÉ; LANGENHOVE, 1999) na relação com os grupos a que pertencemos e nas atividades que desenvolvemos. Refere-se a um pertencimento e a uma organização de si como forma de se construir a partir das relações dialógicas.

A teoria do posicionamento (HARRÉ; LANGENHOVE, 1999), parte da concepção de que as interações verbais tomam forma de construções identitárias de si e do outro. Assim, a identidade refere-se a um conjunto de posicionamentos organizados semioticamente como uma estética de si que é significada pela interação com o outro. As escolhas e formas de atuar como professor correspondem aos posicionamentos de cada docente e têm significados e valores específicos para cada um de acordo com a construção da sua história pessoal.

Identidade e posicionamento nos fazem dialogar com a situação atual do professor. Ele necessita agregar novos conhecimentos sobre outras áreas acadêmicas, entretenimentos, tecnologias, às quais possam contribuir para as relações professor e aluno que, não só na $E A D$, mas também, no presencial têm necessitado que o professor seja mais dinâmico, interativo e procure construir conhecimento junto com o aluno procurando compreender a situação que esse aluno, jovem ou não, vive cotidianamente na sociedade.

Para isso, o nosso entrevistado, Dan, procura levar para o presencial suas produções para a EAD, já que o conteúdo a ser trabalhado é o mesmo do presencial.

[...] no final, eu sempre trazia um vídeo pra eles verem da educação a distância. Eu levava pra aula de educação presencial e mostrava, por que aí ficava pensando, por que eu não vou levar esses vídeos que eu faço? [...] então, eu levo outra face da educação, que não é presencial, levo pra lá também e eles já pedem: - Professor trouxe outro pra gente ver? Às vezes, levo uns muito específicos, contextualizados, por exemplo, no seminário que está sendo apresentado [...] (Professor Dan)

Nesta fala, percebemos a dialogicidade existente nas relações professor e aluno que contribuem para a construção identitária de ambos. 0 dialogismo representa uma forma de pensar os processos de manifestações e interações sociais, conceito desenvolvido por Bakhtin (2000), que consiste nas relações eu-outro e que possibilita a construção do conhecimento por meio desta interação.

Para que suas produções sejam realizadas, Dan precisou aprimorar seus conhecimentos gerais, buscou estudar roteirização de cinema para trabalhar na produção de seus vídeos.

[...] eu to roteirizando. Eu to entendendo agora de estrutura de roteiro cinematográfico, ta? Eu entrei na educação a distância, e eu pensava com o diretor e a diretora o que nós íamos gravar, mas eu não escrevia roteiros, até que eu comecei a me tornar viciado em roteiro de cinema. Comecei a ler, devorar, milhares de livros, comecei a entender a estrutura, comecei a pensar nisso. Aí comprei mais bibliografias a respeito de estrutura de roteiro né, e penso nesse processo de adequação de questões da educação a distância e aí aparece esse professor lá que tá atuando e que tá repensando nesse processo de enquanto identidade [... (Professor Dan) 
Para Bauman (2005), a identidade passa por um processo contínuo de construção permanecendo incompleta. Isso nos leva a perceber que, em cada fala do docente Dan, ele encontra-se em constante crescimento como pessoa, como profissional mesmo que, em alguns momentos, percebamos algumas confusões de pensamento neste processo de desenvolvimento.

Já a criação de personagens para atuar nos vídeos, videopoemas, vídeo-aulas e podcasts nos faz compreender que a atuação está presente no jeito como Dan é professor, o que permite que ele trabalhe o conteúdo programático de forma inovadora. Aristóteles (384 a.C a 322 a.C), na Grécia antiga, escreveu em sua obra "Poética" que Personagem e Pessoa possuem diferenças em seus significados.

Para Brait (2006), dois aspectos essenciais são encontrados na obra "Poética" de Aristóteles, a personagem, como reflexo da pessoa humana, não só com o que é "imitado" ou "refletido", mas com sua verossimilhança, e "a personagem como construção, cuja existência obedece às leis particulares que regem o texto" (BRAIT, 2006, p. 29). No entanto, ao longo dos séculos surgiram outras definições para Personagem que diferem do que Aristóteles descreveu. Estas definições variam nas relações como ser fictício-pessoa.

Entretanto, quando tratamos de identidade e construção de personagens pelo professor, percebemos a aproximação das características do personagem e do professor em muitos momentos em suas falas e modo de atuar, o que acaba gerando confusões mesmo para o docente se pensarmos na separação quando é cada um, pois, possuem características em comum ainda que se deseje que sejam singulares.

[...] quando a gente tá olhando pra câmera assim oh, é a gente e a câmera é mais fácil de lidar assim do que 700 pessoas que estão vendo você agora num outro lugar que dialogam, é confuso pra mim ainda, acho que essa forma de desabafo é porque há uma certa confusão mesmo de se pensar como professor ainda nessa modalidade [...] (Professor Dan)
[...] como é essa confusão ai, de como é essa construção de identidade do sujeito que ta lá no momento da atuação. Lembra daquele momento que mostrei pra você especificamente? (sim) eu disse oh aqui começou a atuação eu to esperando, eu to experimentando a câmera, eu to com o controle da câmera na minha mão [...] (Professor Dan)

Se, acreditamos que o professor da EAD tem como uma das suas características identitárias a criação de personagens para atuar nos vídeos, podcasts, videopoemas ou mesmo nas vídeo-aulas, podemos dizer que a sua atuação diante das telas é semelhante à de um ator nos cinemas ou no teatro. Mudando a forma de trabalhar do professor e possibilitando refletir sobre a atuação do professor da EAD como uma nova perspectiva de ser professor, é possível criar outra forma de pensar esse professor com a criação de personagens para a EAD.

Para a produção dos seus materiais para as aulas via-satélite, Dan precisou criar alguns personagens para atuar nos podcasts.

[...] fazendo a explanação de determinados conteúdos eu uso da voz, você vai ver nos podcasts eu uso da voz, só não vou fazer agora de frente da câmera eu vou dar os arquivos de áudio depois [...] tem um personagem que eu faço que, às vezes, ele volta, eu faço esse personagem, (como é esse velho) não, esse velho já é, esse velho já leu o Dom Quixote [...] (Professor Dan)

A forma como ele planeja, organiza e publica no AVA, representa características da sua identidade virtual como professor e o uso da criatividade e imaginação para planejar e executar as produções dos materiais que serão postados posteriormente no AVA reflete também suas características pessoais. Outro jeito de perceber as relações professor e personagem refere-se às possibilidades de atuação performática. Esta relação entre personagem e atuação nos faz rever os conceitos do teatro no que se refere às contribuições para a construção do professor.

Na construção do ser professor da EAD do nosso entrevistado, os posicionamentos assumidos ao longo 
da sua vida profissional são construídos pelas vozes que compõem sua identidade como professor. Ele cria personagens para atuarem nos podcasts gravados por ele nos quais é possível perceber as diferenças na entonação de sua voz. A construção de personagens também está presente nas atuações em seus vídeos, em algumas vídeo-aulas e nas interpretações dos textos literários escritos que são transformados em oralidade.

As personagens criadas pelo professor são representadas pelo ator, que, nestes momentos, também é o nosso professor. De acordo com o dicionário de termos técnicos e gírias do teatro, ator é aquele que cria, interpreta, representa uma ação dramática [...] com o uso da sua voz, corpo e emoções ao simples texto concebido pelo dramaturgo com o objetivo de transmitir ao espectador as ações dramáticas propostas (DESVENDANDO O TEATRO, 2012, online).

Falar sobre seu jeito de ser professor na EAD fez com que Dan repensasse sobre outra forma de o professor trabalhar o conteúdo programático na EAD e que tem a ver com a criação de videopoemas, podcasts, ou mesmo quando recita poemas também no presencial.

[...] como é que é esse processo de discussão do professor que oraliza a literatura, mas que transforma em imagem a literatura, seja numa pré-produção, seja em aula que eu faça ao vivo, como é que é isso assim, como é que é essa discussão, sabe, algo que é interessante? [...]

Os videopoemas, também denominados de poesia visual, vídeo-poesia, poesia em imagem, podem ser vistos como fusão entre poesia e vídeo, poesia digital, [...] "há um deslocamento da poesia, de sua forma canônica de veiculação - o livro - assim como o vídeo perde seu caráter de produto acabado, pois está aberto a interpretações”. (FRAGA, 2004, p. 3). Estes materiais que são produzidos pelo professor compõem sua identidade docente. Uma das suas produções de videopoemas é o "Lorqueando", composto por poemas de Garcia Lorca, em que Dan interpreta esses poemas em espanhol, transformando em oralidade e imagem o que antes estava apenas no papel.

Uma característica do videopoema é que ele é produzido e veiculado pela internet.

Assim, os videopoemas, além de possuírem características técnicas diferentes, também abrangem desde a arte abstrata até a expressão singela e ingênua com palavras, sons e imagens de pessoas comuns (teoricamente não-poetas). [...] possui muito da ludicidade do poema tradicional com as palavras e do movimento icônico do videoclip musical (LIMA, 2008, p. 7).

E o que o avanço tecnológico tem a ver com a construção identitária do professor da EAD?

A educação tem se apropriado de novos instrumentos como mediadores das relações professor-aluno como as tecnologias a serem usadas nas salas de aula ou as tecnologias para serem utilizadas na produção das vídeo-aulas, no caso da EAD. A linguagem continua sendo o mediador principal nas relações de ensino e aprendizagem, mas ela não pode ser representada apenas pela linguagem falada, escrita, mas também, pela linguagem virtual que engloba estas duas, a linguagem falada e a escrita que dialogam entre si e com os outros.

A dimensão axiológica da tecnologia adquire relevância na acção educativa, entendida como a abordagem de processos educativos associados à polifonia discursiva da vida quotidiana e integradora de uma concepção de tecnologia irremediavelmente vinculada à formação e à educação da pessoa humana. (AIRES, 2003, p. 24)

A linguagem virtual é uma linguagem social por possuir um discurso próprio a partir das formas de escrever, de falar e também pelas possibilidades de comunicação existentes na realidade virtual, o que nos faz refletir acerca do uso das tecnologias como possibilidades de expressão humana.

As tecnologias digitais propiciam maior interatividade, cooperação, autonomia e desenvolvimento da 
cognição a partir do seu uso, pois a tecnologia amplifica a imaginação permitindo o compartilhamento e a relação entre os grupos, possibilitando o desenvolvimento da Inteligência Coletiva, teoria desenvolvida por Lévy (2007). Para ele, as inteligências individuais são somadas e compartilhadas por toda a sociedade a partir do surgimento das novas tecnologias possibilitando trocas de conhecimento e aprendizagens coletivas. "Ela possibilita a partilha da memória, da percepção, da imaginação. Isso resulta na aprendizagem coletiva, troca de conhecimentos" (Lévy, 2007, p.8). Só existe "Inteligência Coletiva" se houver cooperação competitiva (relacionada às relações sociais) ou competição cooperativa (relacionada à liberdade).

O conceito de "inteligência coletiva" leva-nos a repensar na criação de uma nova forma de linguagem, de comunicação que, consequentemente, interferirá nas formas de organização social. Ela tem como problema descobrir, inventar um além da escrita, um além da linguagem que possibilitará que a informação seja distribuída e coordenada por toda parte, a partir da interação social de forma mais universal. A superação de um novo limite pelo homem no qual ele possa inventar algum atributo do humano que seja tão essencial quanto a linguagem, podendo ser superior à criação e ao uso da linguagem, possibilitará novas formas de comunicação (LÉVY, 2003).

É uma inteligência distribuída por parte, incessantemente valorizada, coordenada em tempo real, que resulta em uma mobilização efetiva das competências. Acrescentemos à nossa definição este complemento indispensável: a base e o objetivo da inteligência coletiva são o reconhecimento e o enriquecimento mútuos das pessoas, e não o culto de comunidades fetichizadas ou hipostasiadas. (LÉVY, 2003, p. 28-29).

Ainda hoje acreditamos que pensar no uso de tecnologias pelo professor ou pelo aluno vai além do conhecimento do uso da internet, requer que os professores e alunos sejam letrados digitais.

Isto é, professores e alunos que se apropriam crítica e criativamente da tecnologia, dando-lhe significa- dos e funções em vez de consumi-las passivamente. Portanto, o que esperamos é que o letramento digital seja compreendido para além de um uso instrumental (FREITAS, 2011, p. 25).

O letramento digital possibilita diferenciar a leitura e a escrita no papel pela leitura e escrita digital, o que permite identificar uma forma de utilização da tecnologia em benefício da educação.

A web 2.0 possibilitou o aprimoramento do AVA que disponibiliza chats, fóruns, vídeos, podcasts que são interfaces de interação social. Já a aprendizagem aberta propicia a aprendizagem por meio de diversas mídias, como blogs, wikis e listas de discussão como expansão da aprendizagem aberta que proporciona a aprendizagem colaborativa para aquisição da construção de conhecimento.

Uma das grandes marcas da cibercultura é a expansão da aprendizagem aberta que tem sido favorecida pelo movimento de conteúdo aberto. 0 movimento de conteúdo aberto na web tem crescido não apenas com tecnologias de download gratuito e "open source", mas também com conhecimento científico e materiais educacionais que têm sido compartilhados na internet. (OKADA; SANTOS, 2008, p. 5)

Pensar no letramento digital nos faz rever a forma como a internet está sendo utilizada a favor da construção do conhecimento, seja pelo aluno e/ou pelo professor da EAD. Nesse sentido, percebemos a necessidade de o professor repensar quais são os seus posicionamentos diante das tecnologias digitais, como está sendo construída sua identidade virtual, seja utilizando as tecnologias como mediadoras no desenvolvimento e construção de novas formas de proporcionar a aquisição de conhecimento ao aluno utilizando as interfaces disponibilizadas no AVA, que possibilita criar e postar os materiais de trabalho, seja utilizando as tecnologias como instrumentos para a construção dos seus materiais nas formas de produção e atuação do professor que a utilizará para disponibilizar suas produções numa proposta de construção de conhecimento. 


\section{CONSIDERACÕ̃ES FINAIS}

A combinação educação e tecnologia nos possibilitam investigar sobre a identidade docente. A educação a distância mais especificamente nos faz refletir sobre as possibilidades de usar a arte e a estética na construção dialógica docente-aluno. $\mathrm{Na}$ educação, compartilhar o uso de técnicas do teatro e do cinema nos faz acreditar que essas artes têm muito a colaborar como mediadores na relação professor-aluno para a construção do conhecimento possibilitando novas formas de ver e interpretar o que se deseja apreender.

A educação a distância, possibilita que o professor utilize os meios tecnológicos para elaborar, construir ou exibir suas aulas utilizando as tecnologias para a produção dos vídeos e para a filmagem das vídeo-aulas.

Essa nova forma de olhar a partir de um instrumento tecnológico utilizado no cinema pelas mídias é o que media a construção identitária do nosso entrevistado, pois representa um fator importante para a construção do professor da EAD por favorecer que ele

\section{REFERÊNCIAS}

AIRES, L. Do silêncio à polifonia: contributos da teoria sociocultural para a educação online. Universidade Aberta. Dezembro de 2003. Disponivel em: <https:// repositorioaberto.uab.pt/bitstream/10400.2/146/1/ Revista-Discursos23-35.pdf>. Acesso em: 28 abr. 2011.

BAUER, M. W; GASKELL, G. Pesquisa qualitativa com texto, imagem e som: um manual prático. Traduzido por Pedrinho A. Guareschi. 2. ed. Petrópolis, RJ: Vozes, 2003.

BAUMAN. Zigmunt. Identidade: entrevista a Benedetto Vecchi. Tradução: Carlos Alberto Medeiros. Rio de Janeiro: Zorge Zahar. 2005. utilize esses instrumentos como mediadores nos processos construtivos identitários, utilizando a própria imagem para as suas produções. São contribuições simbólicas mediadas por máquinas semióticas que produzem imagens ao mesmo tempo em que possibilitam ao professor ser imagem.

Acreditamos que o professor da EAD tem como uma das suas características identitárias a criação de personagens para atuar nos vídeos, podcasts, videopoemas, ou mesmo nas vídeo-aulas e que a sua atuação diante das telas é semelhante à de um ator nos cinemas ou no teatro. Mudando a forma de trabalhar do professor e possibilitando refletir sobre a atuação do professor da EAD como uma nova perspectiva de ser professor, é possível criar outra forma de pensar esse professor como personagem da EAD. Entendemos que o personagem pode ser criado em diferentes situações da vida cotidiana e pode ser visto como uma das identidades assumidas em determinados momentos e circunstâncias por cada pessoa.

BAKHTIN. M. Estética da Criação Verbal. 3. ed. São Paulo: Martins Fontes, 2000.

BRAIT, Beth. A personagem. 8. ed. São Paulo: Ática, 2006.

BORGES, F. T.; LINHARES, R. N. Imagem e narrativa: a construção dialógica da fotografia na pesquisa qualitativa em ciências humanas. Revista Educação em Questão. Natal-RN, v. 33, p. 128-149, 2008. Disponível em: <http://www.revistaeduquestao.educ.ufrn.br/ pdfs/EQ_33_web.pdf >. Acesso: 14 mar. 2011.

CRESWELL, J. W. Projeto de Pesquisa: métodos quali- 
tativos, quantitativos e mistos. Porto Alegre: Artmed, 2007.

DESVENDANDO O TEATRO. 2012. Disponível em: <http://www.desvendandoteatro.com/oteatro.htm>. Acesso em: 18 mar. 2012.

FRAGA, A. A. Imagem, performance e texto na videopoesia. Disponível em: <http://www.letras.ufmg.br/ atelaeotexto/pesquisaadriana.htm. 2004>. Acesso: 18 mar. 2012.

FREITAS, M. T. A. Escola, tecnologias digitais e cinema. Juiz de Fora: UFJF. 2011.

HALL. A identidade cultural na pós-modernidade. 10. ed. Rio de Janeiro: DP\&A. 2005.

HARRÉ; VAN LAGENHOVE. Positioning Theory. Massachusetts: Blackwell Publishers, 1999.

Recebido em: 7 de julho de 2012 Avaliado em: 20 de julho de 2012 Aceito em: 29 de julho de 2012
LÉVY, Pierre. A inteligência coletiva. Por uma antropologia do ciberespaço. 4. ed. tradução L. P. Rouanet. São Paulo, SP: Edições Loyola, 2003.

LIMA, L. R. 0 vídeo-poema como performance: Movimento e corporeidade virtual da palavra. Revistas Tabuleiro de Letras. Linguagens: Práticas, Discursos e Mediações. Ano 1. P. 1-11No. 01 - junho/2008. Disponível em: <http://www.tabuleirodeletras.uneb.br/secun/ capa_edicao1.htm>. Acesso: 18 mar. 2012.

OKADA, S.; SANTOS, E. Co Learn: ciberconferência e cibermapeamento para aprendizagem colaborativa aberta em cibercomunidades. In: II SIMPÓSIO NACIONAL DA ABCIBER ASSOCIAÇÃO BRASILEIRA DE PESQUISADORES EM CIBERCULTURA. São Paulo/SP - PUC-SP - 10 a 13 de setembro de 2008.
1 Mestranda em Educação, UNIT, Aracaju, SE, bolsista PROSUP-CAPES.
Pós-graduada em Docência e Tutoria em EAD, UNIT, SE. Integrante do
Grupo de Pesquisa ECDH. Graduada em Tecnologia em Processamento de
Dados pela Faculdade de Economia e Processamento de Dados de Foz do
Iguaçu-Pr, FEPI (1997). Graduada em Psicologia pela Universidade Tiraden-
tes, Aracaju, SE (2010). E-mail: angelicapiovesan@hotmail.com
2 Professora Titular da Universidade Tiradentes (UNIT) no Programa de
Pós-Graduação em Educação. E-mail: fabricia.borges@gmail.com 